\title{
Energy Saving in Papermaking by Application of Hybrid Calcium Carbonate
}

\author{
Min Woo Lee, * Sun Young Jung, and Yung Bum Seo † \\ Hybrid calcium carbonate (HCC) is prepared by pre-flocculating calcium \\ oxide and ground calcium carbonate (GCC) with ionic polymers, and by \\ injecting carbon dioxide to the pre-flocculated flocs until termination of the \\ reaction at neutral $\mathrm{pH}$. When used in papermaking, $\mathrm{HCC}$ gave higher bulk, \\ higher stiffness, and higher tensile strength than GCC did. Furthermore, \\ when higher wet pressing pressure was applied to the paper containing \\ HCC, higher solid content was achieved with still better stiffness, \\ smoothness, and tensile strength in comparison with the paper containing \\ GCC. Actually, very high bulk of the HCC containing paper was \\ compromisingly reduced to obtain high solid content by applying higher \\ wet pressing pressure. Higher solid content achieved by combination of \\ HCC technology and higher wet pressing pressure resulted in paper drying \\ energy savings of more than $10 \%$, while a high quality of all the essential \\ printing paper properties was maintained. Drying energy savings may \\ contribute to greenhouse gas $(\mathrm{GHG})$ reduction and lowering of the paper \\ production cost.
}

Keywords: Hybrid calcium carbonate; Wet pressing; Solid content; Drying energy savings; Paper bulk; Paper stiffness; Brightness; GHG reduction

Contact information: Department of Bio-based Materials, Chungnam National University, Daejun, Yousung-Gu, Gung-Dong, 305-764, Republic of Korea; *: Now in Hansol Paper, Ltd., Seoul in Republic of Korea; †: Corresponding author: ybseo@cnu.ac.kr

\section{INTRODUCTION}

Manufacturing of paper requires a large amount of energy, especially in the drying section (Paulapuro 2000). Increasing the solids content in the wet pressing process will lower the drying energy. For instance, it is known that a $1 \%$ increase of solids content after wet pressing may reduce 4\% steam consumption in the dryer section (Laurijssen 2013). Energy savings in papermaking can provide large benefits for both profitability and reduction of greenhouse gas $(\mathrm{GHG})$ emissions. The removal of water from the paper wet web after wet pressing stage needs heat evaporation and becomes extremely expensive. To increase the solid contents before drying section, wet paper web needs high wet pressing pressure (Paulapuro 2000) or high filler content (Sutman 2011). High wet pressing pressure may cause 'crushing' to damage the paper structure (Hubbe et al. 2020). High filler content in paper increases the solid content at wet pressing process, but it can yield underspecification products with respect to strength properties.

Replacing chemical pulp with inexpensive inorganic materials such as calcium carbonate without loss of key paper properties in papermaking is a dream come true for the papermakers, and beneficial for forest conservation and production cost savings (Svending et al. 2019). Actually, achieving a 1 to $2 \%$ increase of inorganic filler content in printing paper without lowering essential properties should be a great challenge in paper mill at 
present. To produce highly filled paper, lumen loading of fillers by co-refining the fillers and the wood fibers (Bovin and Carnö 1977; Bown 1985; Kumar et al. 2011), preflocculation of fillers by making flocs of PCC (precipitated calcium carbonate) or GCC (ground calcium carbonate) by applying ionic polymers (Gill 1993; Hjelt et al. 2008; Sang et al. 2012; Seo et al. 2012, 2018), and agglomeration of fillers (Sappänen et al. 1994) were studied. Those pre-flocculation and agglomeration methods decreased the surface area of the fillers by making flocs with multiple of filler particles, and allowed more hydrogen bonding area between wood fibers, resulting in an increase of strength properties of the paper. High bonding properties of paper sheet by those methods allowed more addition of fillers if other essential properties are acceptable. However, those filler pre-flocculation and agglomeration methods do not improve bulk and stiffness of paper sheet, which are the most difficult properties to achieve in developing high filler loaded paper.

Other approaches such as "Superfill," which was made by in-situ $\mathrm{CaCO}_{3}$ formation on the fractionated fines (Silenius 2002) and co-flocculation of fibrous fines and fillers improved paper strength and smoothness, but not bulk (Gavelin 1985). Cellulosenanofibrils also have gained attention as the filler-modifying materials for high-loading paper due to its high surface area and bonding ability (Ottesen et al. 2016; He et al. 2016; Lourenco et al. 2019). High strength properties were obtained by cooking of starch in the presence of fillers. The cooked filler-starch mixture was dried and ground to produce papermaking fillers (Zhao et al. 2006; Deng et al. 2010). Recently pre-flocs by adding polymers to filler-starch mixtures can increase the strength of filler-loaded paper by enhanced filler bondability (Li et al. 2016). However, they still had difficulties to keep the bulk and stiffness. Hybrid calcium carbonate (HCC) was prepared by producing preflocculated flocs with GCC and calcium oxide and then by injecting carbon dioxide to the flocs to make semi-rigid agglomerates of the GCC and newly formed PCC from the calcium oxide (Jung and Seo 2015a; Jung and Seo 2015b; Choi and Seo 2016; Choi et al. 2018; Kang et al. 2020). It was demonstrated that the paper containing $40 \% \mathrm{HCC}$ had equivalent physical properties to the paper containing 30\% GCC as long as $3 \mathrm{wt} \%$ cationic starch was added to the HCC containing paper for supplementing low bonding properties (Kang et al. 2020). In that case, there were no loss or even better properties of tensile strength, bulk, stiffness, and smoothness with $10 \%$ higher content of filler. The HCC allowed the papers to improve both bulk and tensile strength simultaneously, the properties of which were almost impossible to go together in conventional papermaking.

The present study investigated the effect of applying more wet pressing pressure to the HCC containing paper that already had high bulk and determined how much solid content increased at the expense of bulk decrease and how much physical properties changed in comparison with the GCC-containing paper. The property comparison of the $\mathrm{HCC}$ containing paper to the pre-flocculated GCC containing paper were also made.

\section{EXPERIMENTAL}

\section{Materials and Handsheet Preparation}

The GCC was donated by Omya Korea Inc. located in South Korea, and its mean size were reported as $2.0 \mu \mathrm{m}$. Calcium oxide was purchased from Korea Showa Chemicals Co. As a retention aid for papermaking, cationic PAM (C-PAM. MW 5 to 7 million g/mol. $+5 \mathrm{meq} / \mathrm{g}$ ) from CIBA Specialty Chemical Korea was used at $0.1 \%$ based on the dry weight of the papermaking furnish. To make the filler containing handsheets, a mixture (20:80) of 
commercial softwood bleached kraft pulp (SwBKP; a mixture of hemlock, Douglas fir, and cedar) and hardwood bleached kraft pulp (HwBKP; a mixture of aspen and poplar) were used as the wood fiber furnish, both of which came from Canada. These wood pulps were refined together in a laboratory Hollander beater until their freeness reached to $500 \mathrm{~mL}$ CSF (TAPPI T227 om-99). Then, after mixing fibers and fillers to make handsheets of 30 and 40wt $\%$ fillers, handsheets were prepared with $60 \mathrm{~g} / \mathrm{m}^{2}$ basis weight (TAPPI T205 sp95). It was difficult to meet the exact filler content of 30 and $40 \mathrm{wt} \%$; however, once the filler content was closely fixed to the target content, there was almost no variation in the filler content per each type of filler by making handsheets with the same amount of the furnish. The ash content (TAPPI 413 om-93), bulk (TAPPI T411 om-97), tensile strength (ISO 1924), Bekk smoothness (TAPPI T479 cm-99), ISO brightness (ISO 2470), opacity (ISO 2471), and Gurley stiffness (TAPPI T543 om-00) of the handsheets were measured according to the standard methods.

\section{Preparation of HCC and Pre-flocculated GCC}

To prepare pre-flocculated GCC (pGCC), $0.02 \%$ cationic PAM, the same PAM as the retention aid, and $0.02 \%$ anionic polymer (Perform SP7200, MW 0.5 million g/mol -5.0 to $-3.0 \mathrm{meq} / \mathrm{mol}$ Hercules, USA) were added to $2.0 \mu \mathrm{m}$ GCC by weight sequentially at $2000 \mathrm{rpm}$. As soon as the GCC flocs were made, their sizes were measured using FlowCAM $^{\circledR}$ (Xu 2002; Seo et al. 2014), and they were called pre-flocculated GCC (pGCC). To prepare HCC, $28.1 \mathrm{~g}$ of calcium oxide was mixed with $50 \mathrm{~g}$ of $2.0 \mu \mathrm{m} \mathrm{GCC}$ in $1 \mathrm{~L}$ water to produce $100 \mathrm{~g}$ of HCC. Initially GCC and calcium oxide were mixed together, and they were pre-flocculated by adding sequentially $0.03 \%$ cationic PAM and $0.04 \%$ anionic polymer based on the dry weight of the solid while stirring at $1000 \mathrm{rpm}$. After the pre-flocculation of two components, carbon dioxide was injected into the pre-flocculated flocs at $30{ }^{\circ} \mathrm{C}$ and at $350 \mathrm{rpm}$ until a neutral $\mathrm{pH}$ was reached. Final composition of HCC was GCC, $50 \mathrm{wt} \%$ and the newly formed PCC, $50 \mathrm{wt} \%$. The sizes and shapes of the GCC, HCC, and pGCC were determined using FlowCAM ${ }^{\circledR}$ and a scanning electron microscope (S-4800 model. Hitachi, Japan). The FlowCAM ${ }^{\circledR}$ dynamic imaging particle analyzer (Benchtop B3 Series, Fluid Imaging Technologies, USA) measured the volume moment mean values $(\mathrm{D}[4,3])$ of the floc diameter $(\mathrm{Xu} 2002)$. A few drops of the filler suspension from three types of fillers were dried on the sample holders for further micrographic study.

\section{Wet Pressing}

It is known that the HCC-containing paper has much higher bulk than the GCCcontaining paper, while keeping high tensile strength and high stiffness from the previous study (Jung and Seo 2015a; Jung and Seo 2015b; Choi and Seo 2016; Choi et al. 2018; Kang et al. 2020). In the previous study, the authors demonstrated that the HCC containing paper could be used for developing highly filled paper without compromising essential mechanical properties (Kang et al. 2020). This time, the authors tried to make use of the high bulk of HCC containing paper for developing the high solid content paper. A lab wet press that was manufactured by the local paper machine manufacturer (Daeil Paper Machine Co., Korea) was employed. It had capability to apply controlled compressive pressure of 500 to 3,000 N/cm to the wet web. Wet pressing pressures of 1,000 and 2,000 $\mathrm{N} / \mathrm{cm}$ were used for the wet handsheets. The density of the paper containing $30 \mathrm{wt} \% \mathrm{GCC}$ came out as $0.62 \mathrm{~cm}^{3} / \mathrm{g}$ at $1,000 \mathrm{~N} / \mathrm{cm}$ pressure, the density of which was in the range of commercial copy paper. For the papers pressed at 2,000 N/cm pressure, suffixes were added to the abbreviation of the fillers such as 'HCC-H'. Blotting papers used at wet 
pressing process were conditioned at $50 \% \mathrm{RH}$ and $23{ }^{\circ} \mathrm{C}$ before use for close monitoring of wet web solid content variations. Solid content was calculated for every handsheet by comparing wet web weight after wet pressing to the dry weight of it.

\section{RESULTS AND DISCUSSION}

\section{Morphology of the Fillers and their Papers}

Micrographs of the filler samples are shown in Fig. 1. As shown in Fig. 1(a), there were many small GCC particles. They will disrupt the inter-fiber hydrogen bonding effectively inside the paper, resulting in low tensile strength (Hubbe and Gill 2016).

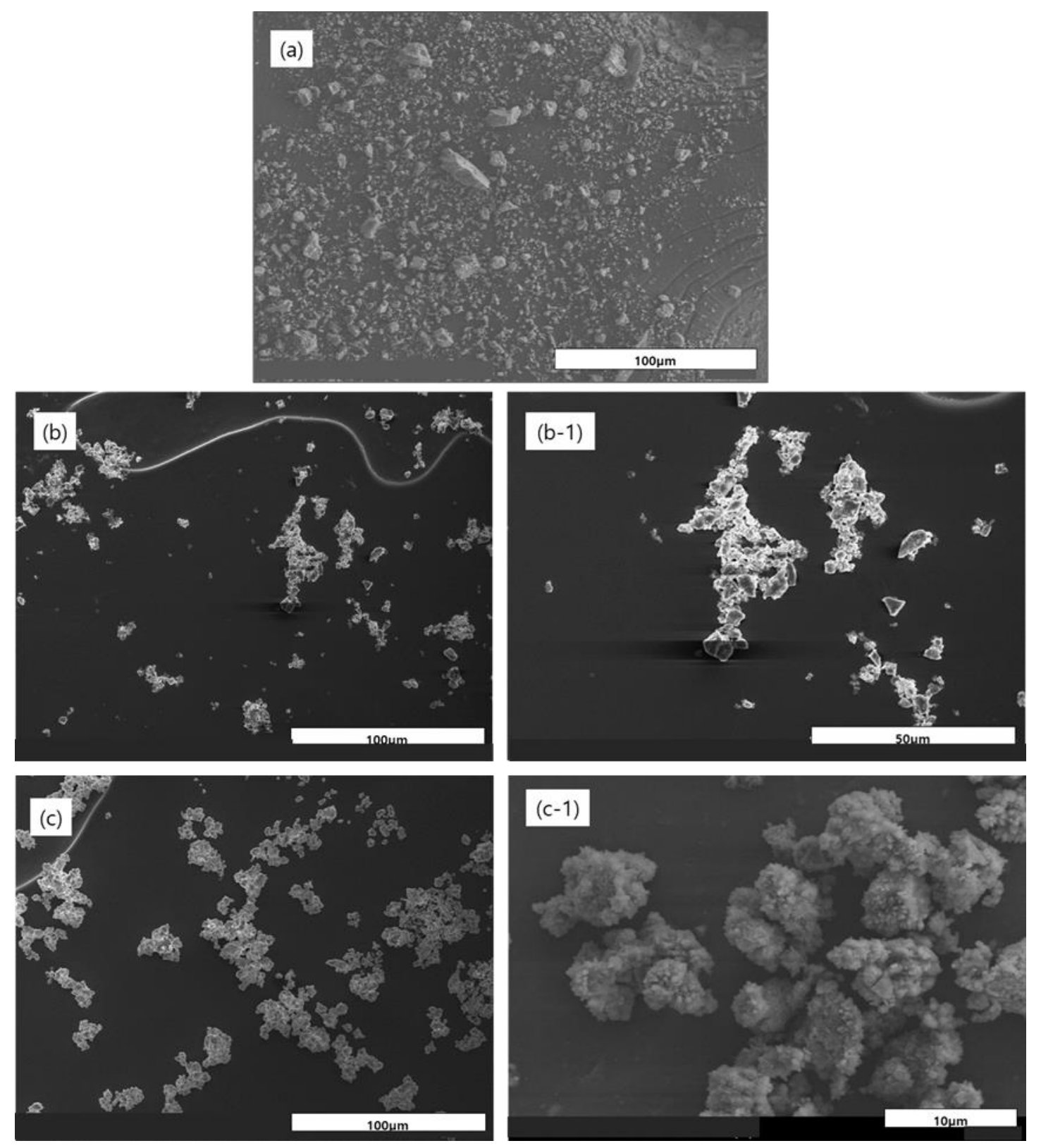

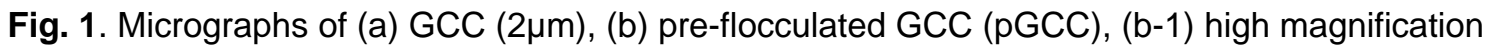
pGCC, (c) HCC, and (c-1) high magnification HCC 
Large flocs are shown in Fig. 1(b) and 1(c), and they will make less disruption of hydrogen bonding than GCC due to their small surface area per unit weight. The preflocculated flocs in Fig. 1(b) should be flattened easily by the compressive pressure applied in the wet pressing process because they were gathered together by the influence of the charges of the ionic polymers (see Fig. 1(b-1)). However, the flocs in Fig. 1(c) should be resistant to some degree to the compressive pressure because they were formed by in-situ calcium carbonate forming process just like PCC (precipitated calcium carbonate) formation process. Figure 1 (c-1) shows a more rigid structure of HCC. HCC seemed to resist compressive pressure applied during the papermaking process, and to induce high bulk in paper. Further explanation of the structure should be found in the references (Jung and Seo 2015; Choi and Seo 2016; Choi et al. 2018; Kang et al. 2020). The HCC in Fig. 1(c) should give high bulk in the handsheets by their size and rigidity, and high tensile strength by their small surface area when compared to the GCC. In the physical property section, it will be shown what can be inferred from these micrographs.

The surface of papers from three different fillers are compared in Fig. 2. From Fig. 2(a) it is apparent that small-size GCC particles covered all over the paper surface because they were distributed evenly as shown in Fig. 1(a). In Fig. 2(b) and 2(c), calcium carbonate particles formed flocs, and those flocs were located between the wood fibers and allowed some clean surface of wood fibers that might form hydrogen bonding. The sizes of the fillers measured by FlowCAM ${ }^{\circledR}$ are presented in Table 1, where it is apparent that pGCC had the largest diameter (Seo et al. 2014). The size of GCC was much bigger than the size that had been stated by the company. It can be expected that different measuring devices made that difference; however, such data were still useful because they were representing the relative size that agreed with the sizes shown in Fig. 1.

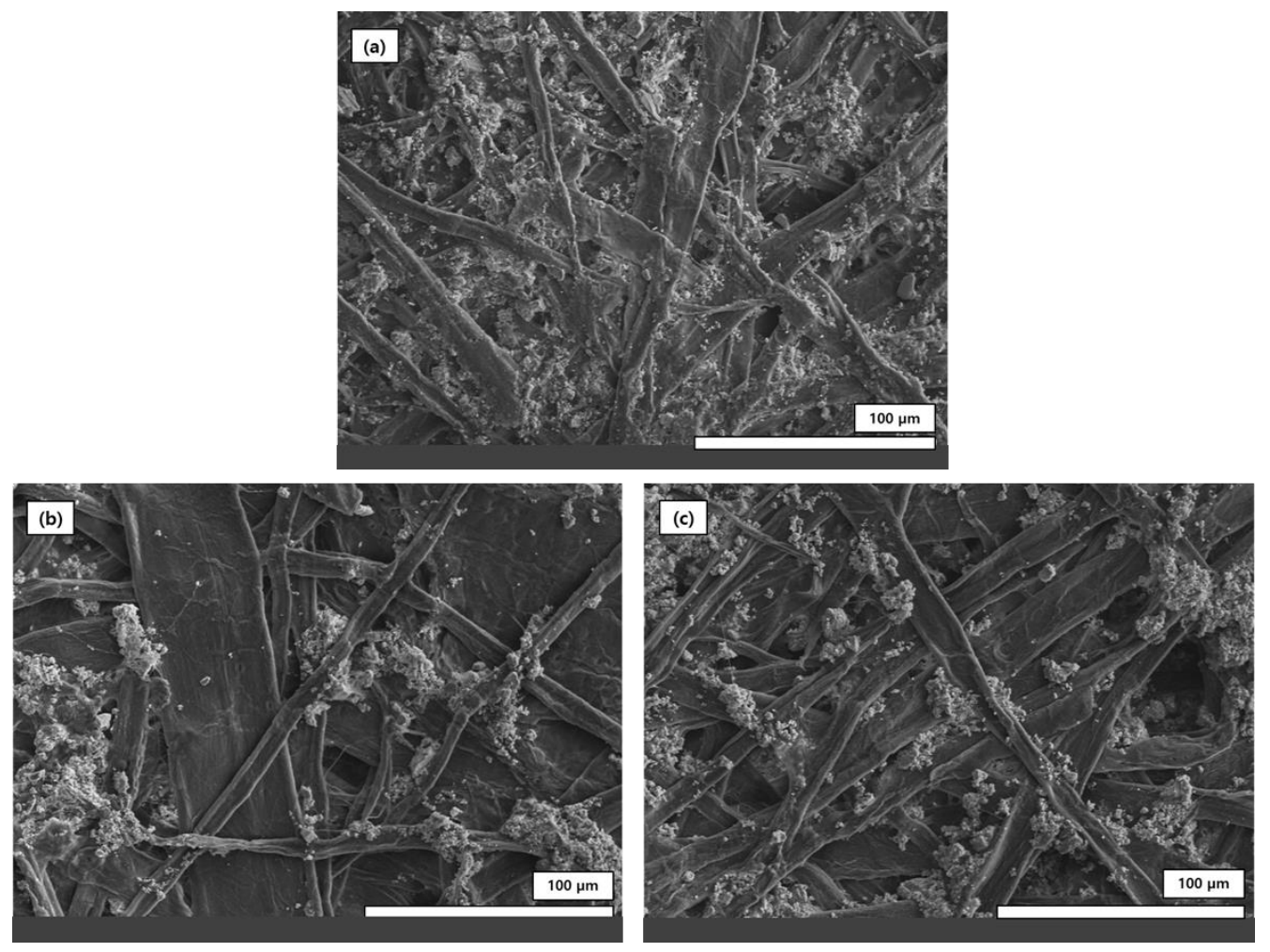

Fig. 2. Micrographs of the papers containing $30 \%$ of (a) GCC $(2 \mu \mathrm{m})$, (b) pre-flocculated GCC (pGCC) and (c) HCC, respectively 
Table 1. Filler Size Measured by FlowCAM ${ }^{\circledR}$ Dynamic Imaging Particle Analyzer (Xu 2002)

\begin{tabular}{|l|c|c|}
\hline Fillers & $\mathrm{D}[4 \mathrm{3}](\mathrm{ABD}), \mu \mathrm{m}$ & Standard Deviation \\
\hline GCC & 7.50 & 1.22 \\
\hline Pre-flocculated GCC (pGCC) & 31.88 & 5.89 \\
\hline HCC & 24.71 & 8.05 \\
\hline
\end{tabular}

\section{Wet Pressing Effect}

Wet webs containing three different fillers were pressed in a roll-type wet press under $1,000 \mathrm{~N} / \mathrm{cm}$ pressure. To investigate the effect of high wet pressing pressure on the wet web containing HCC, the wet-pressing pressure of 2,000 N/cm was also applied. In a real mill situation, wet-pressing pressure is limited by the fact that firstly, the paper bulk and stiffness might become unacceptably low and secondly, paper delamination could happen by the paper crushing at high wet pressing pressure. Paper delamination or crushing may result in low strength and bad formation. The wet-pressing results from the experiment are presented in Fig. 3. At 1,000 N/cm pressure, GCC gave the highest, HCC next, and pGCC, the lowest solid contents. The authors believe that there were many void spaces that were filled with water in the HCC-containing paper inside the wet web after wet pressing than in the GCC containing paper because paper bulk is higher for the HCC containing paper. Water presence in the void spaces should lower the solid contents of $\mathrm{HCC}$ containing paper after wet pressing. For the pGCC, the flocs consisting of large number of GCC particles were located in-between the fibers (Fig. 2(b)), and totally collapsed under the wet pressing pressure, and produce lower bulk paper than GCC. For the paper containing the pGCCs, more fiber surfaces are exposed to the other fiber surfaces without interference of small size filler particles and formed more hydrogen bonding (see Fig. 2(b)). Water could be kept effectively in between hydrophilic wood fibers to result in low solid content. However, the higher solids content of the HCC than that of pGCC is not fully understood. This should be studied further in the future.

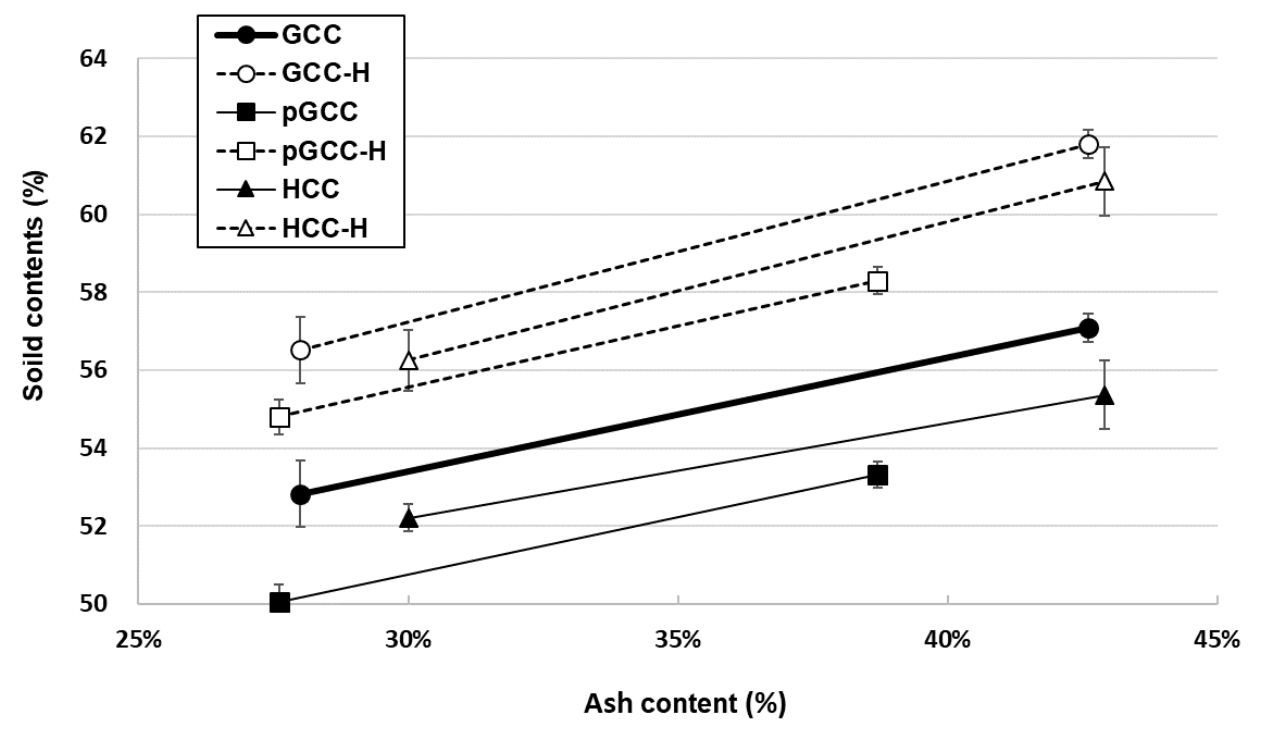

Fig. 3. Solid contents of the papers containing different fillers 
The obvious difference between HCC and the pGCC in sheet structure is that the HCC stays in rigid form while the pGCC was in the form of collapsed clusters of GCC particles under the wet pressing.

When wet pressing pressure was increased as in the case of HCC-H, a large increase of solids content was observed in the paper containing HCC (Fig. 3). About 3\% of solid contents higher than the GCC paper is shown for the HCC-H paper in Fig. 3. In short, a huge increase in solid content was witnessed at high wet pressing pressure for the paper containing HCC in Fig. 3 at the expense of some decrease of bulk, which should be presented in the 'Mechanical Properties' section.

\section{Mechanical Properties}

Figure 4(a) shows the bulk of papers containing different fillers and how much the paper bulk was affected by the high wet pressing pressure.
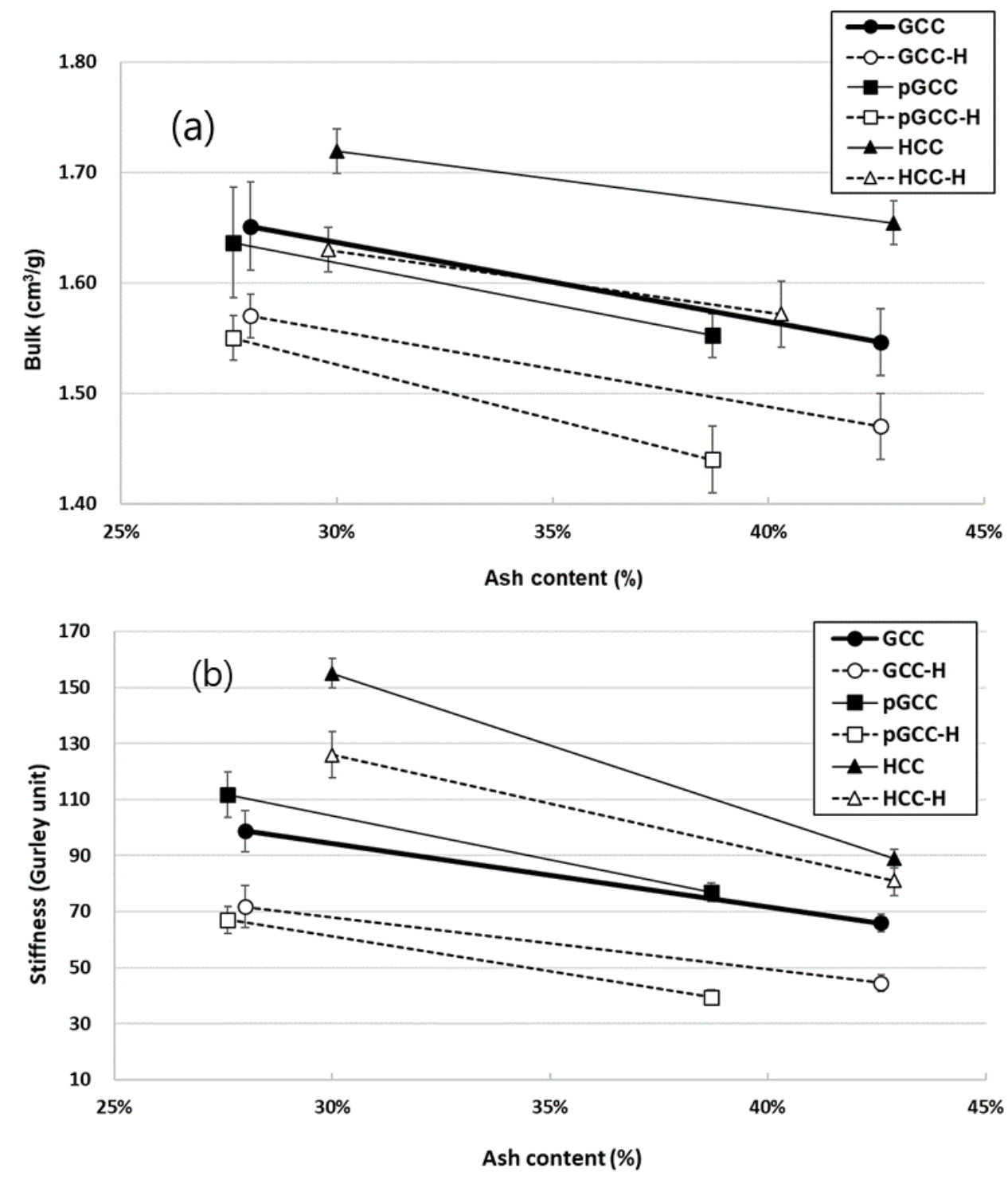

Fig. 4. Bulk and stiffness of the papers containing three different fillers. (a) bulk and (b) stiffness. 
As presented previously in the literature (Jung and Seo 2015a; Jung and Seo 2015b; Kang et al. 2020), the HCC-containing paper always gave remarkably higher bulk than the others, and the one pressed with two-fold higher wet pressing pressure, $\mathrm{HCC}-\mathrm{H}$, kept the bulk equivalent to GCC. The stiffness of the papers containing HCC that were pressed with high wet pressing pressure were still higher than those containing GCC and the pGCC in Fig. 4(b). There might be a critical stiffness value where the stiffness of the GCC-H and pGCC-H were too low to satisfy the commercial paper product spec. And that might be one of the reasons why high wet pressing pressure was not applied to the GCC containing paper even though high solid content could be achieved easily by changing wet pressing pressure.

The breaking length, which is a measure of tensile strength after compensating basis weight differences, is presented in Fig. 5. The breaking lengths of the papers containing pGCCs and HCCs showed little differences among them, while the one containing GCCs gave much lower values (Fig. 5). From the fact that during the application of higher wet pressing pressure, the paper containing HCC experienced a large bulk decrease, but only little difference in breaking length. It was assumed that there were no disastrous events such as crushing or delamination during the wet pressing process. However, this behavior should be confirmed by mill trials.

\section{Physical Properties}

The brightness of the papers containing HCCs were higher than those containing GCC and the pGCC, as shown in Fig. 6(a). This was because a half portion the HCC consisted of the PCC produced by in-situ $\mathrm{CaCO}_{3}$ formation process. For the pGCC, the pre-flocculated flocs lowered the light scattering due to lower surface area than the GCC. Brightness is usually affected positively by the amount of light scattering. For the opacity, the paper containing GCC had the highest opacity because it had individual GCC particles evenly distributed inside the paper and caused the highest amount of surface area and light scattering. The paper containing the pGCC had the lowest opacity because it had the largest floc size (Table 1), and the lowest surface area per weight to lower the scattering coefficient and the opacity.

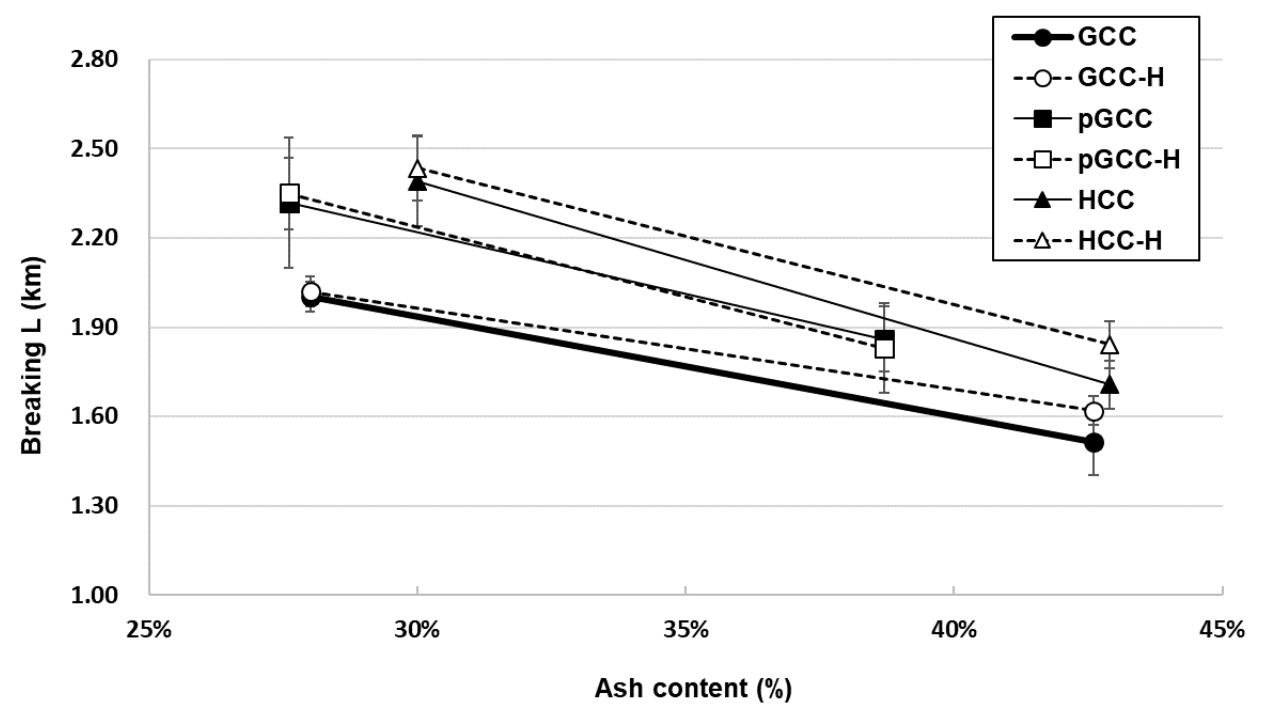

Fig. 5. Breaking length of the papers containing three different fillers 

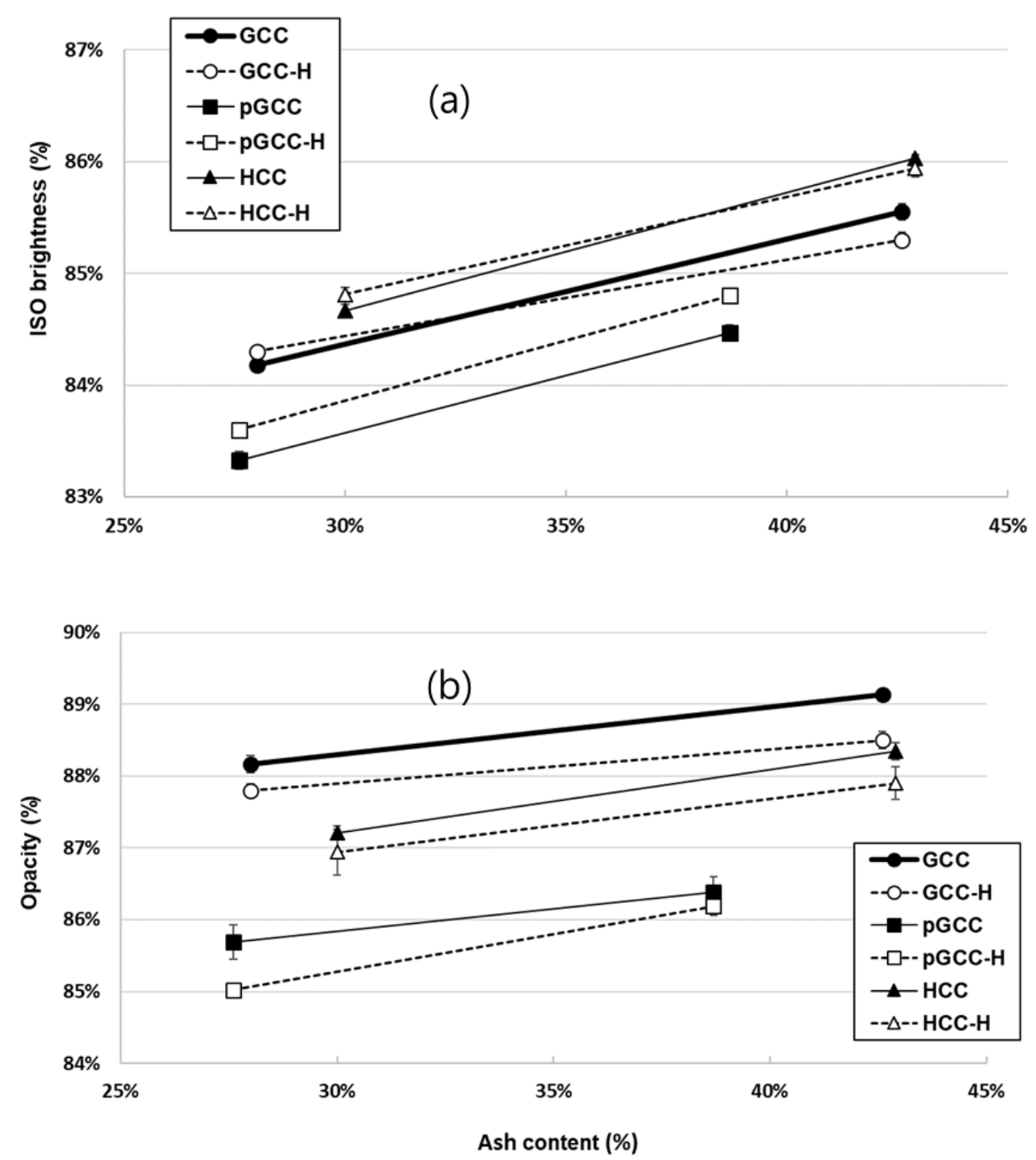

Fig. 6. Brightness and opacity of the papers containing three different fillers. (a) ISO brightness and (b) opacity

The Bekk smoothness value of the papers were measured and are presented in Fig. 7, where it is apparent that the papers containing HCCs gave the smoothness as much as or better than the others. The paper containing the pGCC should be as smooth as the one containing GCC because the flocs should be totally collapsed. However, the HCC had some rigidity to resist against the compressive pressure for developing high bulk during wet pressing, and should give low Bekk smoothness. However, in the previous study listed in the literature (Jung and Seo 2015a; Jung and Seo 2015b; Choi and Seo 2016; Choi et al. 2018; Kang et al. 2020), it was demonstrated that the HCC was partially deformable under the wet pressing condition, but not totally collapsible. Therefore, the three different fillers including the HCC-H gave similar smoothness with overlapped standard deviations. Their response to the calendering pressure should be interesting and be studied in the near future. 


\section{Comparison of the Calculated Physical Properties from the Graphs}

The physical properties of the papers were calculated at fixed ash contents such as 30 and $35 \%$ from the graphs, and the results are shown in Table 2. Those of the GCC-H and the pGCC-H papers were not listed because of a concern that they had too low stiffness to be a commercial products. From the table, the solid contents of the papers processed with GCC30 were compared to those with HCC30-H and HCC35-H.
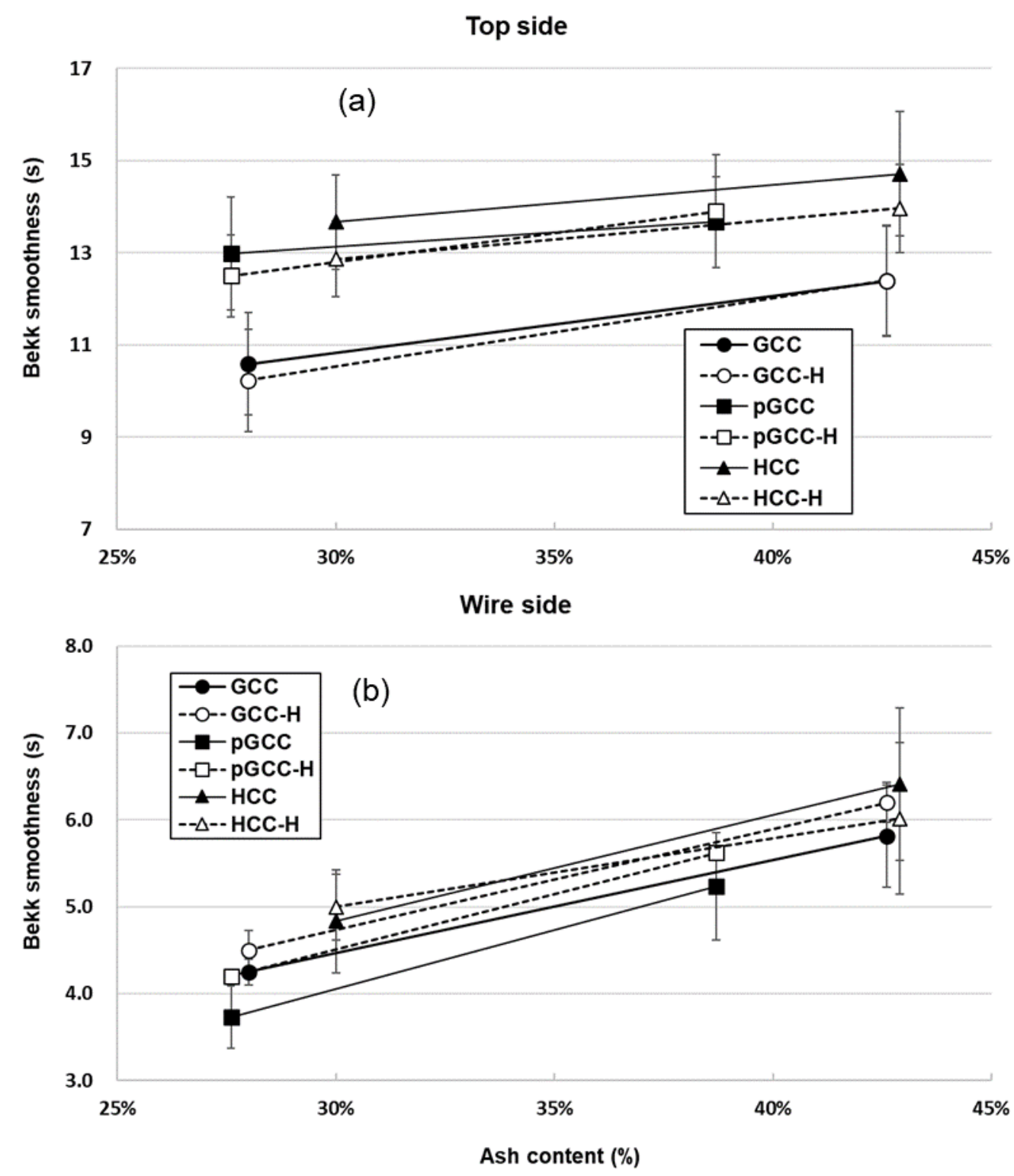

Fig. 7. Bekk smoothness (top and wire side) of the papers containing three different fillers. (a) top side and (b) wire side

Large increases in solid contents for the HCC30-H and HCC35-H were observed: $2.6 \%$ and $4.5 \%$, respectively. There were no decreases in breaking length, stiffness, smoothness, and brightness, but only slight decrease in opacity. When comparing the solids contents of the papers processed with GCC30 to those with HCC30 and HCC35, no increase of solid contents was found, while there were large increases in bulk and stiffness for those with HCC30 and HCC35. As a matter of fact, some of the bulk and stiffness were 
sacrificed, and a large increase of solids content was gained by applying higher wet pressing pressure. Calendering raises smoothness but lowers most physical properties including bulk, stiffness, and tensile strength. Therefore, further study may need to evaluate the physical properties at the equivalent smoothness after calendering. In general, the properties after calendering closely follow those before calendering.

Table 2. Comparison of the Physical Properties Calculated at 30 and $35 \%$ Ash Contents

\begin{tabular}{|l|c|c|c|c|c|c|c|c|}
\hline & $\begin{array}{c}\text { Bulk } \\
(\mathrm{cm} 3 / \mathrm{g})\end{array}$ & $\begin{array}{c}\text { Breaking } \\
\text { length } \\
(\mathrm{Km})\end{array}$ & $\begin{array}{c}\text { Gurley } \\
\text { stiffness } \\
\text { (Gurley unit) }\end{array}$ & $\begin{array}{c}\text { Solid } \\
\text { content } \\
(\%)\end{array}$ & $\begin{array}{c}\text { Bekk } \\
\text { Smoothness } \\
\text { Felt. (Sec.) }\end{array}$ & $\begin{array}{c}\text { Bekk } \\
\text { Smoothness } \\
\text { Wire. (Sec.) }\end{array}$ & $\begin{array}{c}\text { Opacity } \\
(\%)\end{array}$ & $\begin{array}{c}\text { Brightness } \\
(\%)\end{array}$ \\
\hline GCC30 & 1.64 & 1.96 & 95.0 & 53.5 & 10.9 & 4.4 & 88.3 & 84.4 \\
\hline pGCC30 & 1.62 & 2.21 & 106.0 & 50.8 & 13.1 & 4.0 & 85.9 & 83.6 \\
\hline HCC30 & 1.72 & 2.35 & 153.0 & 52.1 & 13.5 & 4.8 & 87.1 & 84.7 \\
\hline HCC30-H & 1.63 & 2.42 & 126.0 & 56.1 & 12.9 & 5.0 & 87.0 & 84.8 \\
\hline GCC35 & 1.60 & 1.78 & 85.0 & 55.1 & 11.5 & 5.0 & 88.6 & 84.8 \\
\hline pGCC35 & 1.58 & 2.05 & 90.0 & 52.2 & 13.5 & 4.5 & 86.1 & 84.2 \\
\hline HCC35 & 1.63 & 2.13 & 130.0 & 53.3 & 14.0 & 5.4 & 87.7 & 85.2 \\
\hline HCC35-H & 1.60 & 2.22 & 110.0 & 58.0 & 12.7 & 5.5 & 87.3 & 85.3 \\
\hline
\end{tabular}

\section{CONCLUSIONS}

1. By the application of both hybrid calcium carbonate (HCC) and higher wet pressing pressure in printing paper, drying energy could be reduced significantly by increasing solid content in comparison with the conventional filler, ground calcium carbonate (GCC).

2. Application of higher wet pressing pressure to the HCC-containing paper than the pressure to the GCC did not lower the stiffness, Bekk smoothness, and the tensile strength of the resultant paper at equivalent or $5 \%$ higher amount of fillers.

3. The excess high bulk and stiffness for the HCC-containing paper were reduced and effectively traded as a means to obtain solid content increase by applying higher wet pressing pressure.

4. The paper containing HCC also gave higher brightness than the one containing GCC due to the presence of precipitated calcium carbonate (PCC) formed during the in-situ $\mathrm{CaCO}_{3}$ forming process included in the HCC preparation.

5. Drying energy reduction for the paper containing HCC can lead to the GHG reduction and to the cost savings in paper mill.

\section{REFERENCES CITED}

Bovin, A., and Carnö, B. (1977). "Factors influencing the efficiency of $\mathrm{TiO}_{2}$ in paper," Svensk Papperstidn. 80(15), 483-486. 
Bown, R. (1985). "Review of methods for increasing filler loadings," Paper Technol. Ind. 26(6), 289-292.

Choi, J. S., and Seo, Y. B. (2016). "Development of hybrid calcium carbonate for high loading paper (III),” J. Korea TAPPI 48(6), 55-61. DOI:

10.7584/JKTAPPI.2016.12.48.6.55

Choi, J. S., Kang, D. S., Han, J. S., and Seo, Y. B. (2018). "Property development mechanism of hybrid calcium carbonate," ACS Sustainable Chemistry \& Engineering 7, 1538-1544. DOI: 10.1021/acssuschemeng.8b05304

Deng, Y. L., Jones, P., McLain, L., and Ragauskas, A. J. (2010). "Starch modified fillers for linerboard and paper grades: A perspective review," Tappi J. 9(4), 31-36. DOI: 10.32964/TJ9.4.31

Gavelin, G. (1985). "Coflocculation of fines and filler particles," Paperi Puи 67(11), 649-653.

Gill, R. A. (1993). "Interactions between polymers and precipitated calcium carbonate filler," Nordic Pulp and Paper Res. J. 8(1), 167-169. DOI: 10.3183/npprj-1993-0801-p167-169

He, M., Cho, B. U., and Won, J. M. (2016). "Effect of precipitated calcium carbonatecellulose nanofibrils composite filler on paper properties," Carbohydrate polymers 136, 820-825. DOI: 10.1016/j.carbpol.2015.09.069

Hjelt, T., Sirviö, J., and Saarela, M. (2008). "Effect of filler clustering on paper properties," Appita J. 61(3), 209-211.

Hubbe, M. A., and Gill, R. A. (2016). "Fillers for papermaking: A review of their properies, usage practices, and their mechanistic role," BioResources 11(1), 2886-2963. DOI: 10.15376/biores.11.1.2886-2963

Hubbe, M. A., Sjöstrand, B., Nilsson, L., Koponen, A., and McDonald, J. D. (2020). "Rate-limiting mechanisms of water removal during the formation, vacuum dewatering, and wet-pressing of paper webs: A review," BioResources 15(4), 96729755. DOI: 10.15376/biores.15.4.Hubbe

Jung, J. K., and Seo, Y. B. (2015a). "Development of hybrid calcium carbonate for high loading paper (I)," J. Korea TAPPI 47(4), 30-37. DOI: 10.7584/ktappi.2015.47.4.030

Jung, J. K, and Seo, Y. B. (2015b). "Development of hybrid calcium carbonate for high loading paper (II) comparison with GCC,” J. Korea TAPPI 47(4), 76-80. DOI: 10.7584/ktappi.2015.47.4.076

Kang, D. S., Han, J. S., Choi, J. S., and Seo, Y. B. (2020). "Development of deformable calcium carbonate for high filler paper," ACS Omega 5, 15202-15209. DOI: 10.1021/acsomega.0c01179

Kumar, P., Negi, Y. S., and Singh, P. (2011). "Filler loading in the lumen or/and cell wall of fibers - A literature review," BioResources 6(3), 3526-3546.

Laurijssen, J. (2013). Energy Use in the Paper Industry - An Assessment of Improvement Potentials at Different Levels, Ph.D. Dissertation, Dutch Kenniscentrum Papier en Karton, The Netherlands Utrecht University, The Netherlands, p. 104.

Li, T., Fan, J., Chen, W., Shu, J., Qian, X., Wei, H., Wang, Q., and Shen, J. (2016). "Coaggregation of mineral filler particles and starch granules as a basis for improving filler-fiber interaction in paper production," Carbohydrate Polymers 149, 20-27. DOI: 10.1016/j.carbpol.2016.04.082

Lourenco, A. F., Godinho, D., Gamelas J. A. F., Sarmento, P., and Ferreira, P. J. T. (2019). "Carboxymethylated cellulose nanofibrils in papermaking: Influence on filler 
retention and paper properties," Cellulose 26, 3489-3502. DOI: 10.1007/s 10570-01902303-5

Ottesen, V., Syverud, K., and Gregersen, Ø. W. (2016). "Mixing of cellulose nanofibrils and individual furnish components: Effects on paper properties and structure," Nordic Pulp and Paper Res. J. 31(3), 441-447. DOI: 10.3183/npprj-2016-31-03-p441-447

Paulapuro, H. (2000). "Wet pressing," in: Papermaking Science and Technology, Papermaking. Part 1, Stock Preparation and Wet End, Fapet Oy, Finland, Chapter 8, p. 287.

Paulapuro, H. (2000). "Wet Pressing - Present understanding and future challenges," in: The Science of Papermaking, Trans. of the XIIth Fund. Res. Symp. Oxford, 2001, (C.F. Baker, ed.), FRC, Manchester, 639-678. DOI: 10.15376/frc.2001.1.639.

Sang, Y., Mcquaid, M., and Englezos, P. (2012). "Pre-flocculation of precipitated calcium carbonate filler by cationic starch for highly filled mechanical grade paper," BioResources 7(1), 354-373.

Sappänen, R., Elftonson, J., and Ström, G. (1994). "Microflocs of clay - Preparations and the effects on paper properties," Helsinki Univ. Technol., Lab for Prod. Chem., Rep., Ser. C. 5, 5-7.

Seo, D. I., Im, W. H., Yoon, H. J., and Lee, H. L. (2012). “The effects of process variables for GCC pre-flocculation on floc and handsheet properties," Nordic Pulp and Paper Res. J. 27(2), 382-387. DOI: 10.3183/npprj-2012-27-02-p382-387

Seo, Y. B., Lee, Y. H., and Chung, J. K. (2014). "The improvement of recycled newsprint properties by in-situ $\mathrm{CaCO}_{3}$ loading," BioResources 9(4), 6254-6266. DOI: 10.15376/biores.9.4.6254-6266

Seo, D. I., Oh, K. D., Im, W, H., and Lee, H. L. (2018). "Hydrolysis of cationic polyacrylamide and its effects on flocculation of ground calcium carbonate," BioResources 13(3), 5303-5318.

Silenius, P. (2002). Improving the Combinations of Critical Properties and Process Parameters of Printing and Writing Papers and Paperboards by New Paper-Filling Methods, Ph.D. Dissertation, Helsinki University of Technology, Laboratory of Paper Technology, Reports, Series A14.

Sutman, F. J. (2011) "The influence of filler content and process additives on wet web strength and runnability," PAPERCON 2011 Conference Proceedings, TAPPI, 919925.

Svending, P., Phipps, J., Lai, R., and Martoni, A. (2019). "Substituting pulp for filler is increasingly attractive for papermakers." TAPPI PaperCon. Indianapolis, USA, Available at: https://fiberlean.com/substituting-pulp-for-filler/

Xu, R. (2002). "Particle characterization," in: Light Scattering Methods, Kluwer Academic Publishers, New York, USA, pp. 199-213.

Zhao, Y., Hu, Z., Ragauskas, A. J., and Deng, Y. (2006). "Improvement of paper properties using starch-modified precipitated calcium carbonate filler," Tappi J. 4(2:, 3-7.

Article submitted: March 3, 2021; Peer review completed: May 8, 2021; Revised version received and accepted: May 15, 2021; Published: May 26, 2021.

DOI: 10.15376/biores.16.3.5011-5023 